\title{
The role of p-Stat3 Y705 immunohistochemistry in glioblastoma prognosis
}

\author{
Sergiu Susman ${ }^{1,2^{*}}$, Radu Pîrlog ${ }^{1}$, Daniel Leucuța ${ }^{3}$, Andrei Otto Mitre ${ }^{4}$, Vlad Adrian Padurean ${ }^{5}$, Carmen Melincovici', \\ loana Moldovan ${ }^{1}$, Doinița Crișan ${ }^{1,6}$ and Stefan Ioan Florian ${ }^{4,5}$
}

\begin{abstract}
Background: In spite of the multimodal treatment used today, glioblastoma is still the most aggressive and lethal cerebral tumour. To increase survival in these patients, novel therapeutic targets must be discovered. Signal transducer and activator of transcription 3 (Stat3), a transcription factor that controls normal cell differentiation and survival is also involved in neoplastic celltransformation. In this study we evaluated the immunohistochemical expression of pY705-Stat3 in patients with primary glioblastoma and determined its prognostic role by correlating it with survival.

Methods: This retrospective study included 94 patients diagnosed with glioblastoma. We determined the localization, number of positive cells, and marker intensity for pY705-Stat3 in these patients with the use of immunohistochemistry. The prognostic role was determined by correlating pY705-Stat3 expression on formalinfixed paraffin-embedded tumour tissues with the patient's survival in univariate and multivariate COX regressions.

Results: We found a statistically significant difference in survival between the patients with more than 20\% pY705Stat3 positive cells and those with less than 20\% pY705-Stat3 positive cells (8.9 months median survival versus 13.7 months medial survival, $p<0.001$ ). On multivariate analyses with the COX proportional hazards regression model including pY705-Stat3 expression, age and relapse status, pY705-Stat3 status was an independent prognostic factor in glioblastoma $(P<0.001)$.
\end{abstract}

Conclusion: The results obtained show that the immunohistochemical expression of pY705-Stat3 correlates with survival in glioblastoma. This study identifies Stat3 as a possible target for existing or new developed Stat3 inhibitors.

Keywords: Glioblastoma, Stat3, Immunohistochemistry, Prognosis

\section{Background}

According to the $2016 \mathrm{WHO}$ classification, glioblastoma is classified as a grade IV, being known to be one of the most lethal brain tumours [1]. Standard treatment includes surgical resection followed by adjuvant radiotherapy and chemotherapy [2]. Despite the multimodal treatment used at present, median survival remains very

* Correspondence: serman_s@yahoo.com

${ }^{1}$ Department of Morphological Sciences, Iuliu Hațieganu University of Medicine and Pharmacy, 6 Pasteur Street, 400349 Cluj-Napoca, Romania ${ }^{2}$ Department of Pathology, Imogen Research Centre, Cluj-Napoca, Romania Full list of author information is available at the end of the article low, and new therapies are required to increase survival in these patients [3].

From a histopathological point of view, glioblastoma is characterized by necrosis and microvascular proliferation, elements that reflect an intra-tumour heterogeneity in terms of cell adaption to hypoxia [1].

Adaptation to hypoxia leads to the specific activation of the genetic programs and signalling pathways that are also involved in the stem-like phenotype or epithelialmesenchymal (EMT) transition, with the subsequent increase in resistance to chemotherapy and radiotherapy [4-6]. Recent studies that have attempted to decode the molecular mechanisms involved in hypoxic cell

(c) The Author(s). 2019 Open Access This article is distributed under the terms of the Creative Commons Attribution 4.0 International License (http://creativecommons.org/licenses/by/4.0/), which permits unrestricted use, distribution, and 
adaptation in glioblastoma have shown that the major signalling pathways activated in hypoxia are those of the hypoxic inducible factor $1 \alpha$ (HIF-1 $\alpha)$ vascular endothelial growth factor (VEGF), transforming growth factor beta (TGF $\beta$ ), mammalian target of rapamycin (mTOR), CD133, as well as of signal transducer and activator of transcription 3 (Stat3) [6-9].

Stat3 protein is a regulator of cell survival, proliferation, differentiation and apoptosis; it also regulates cell adaptation to hypoxia by stimulating angiogenesis in several types of cancers [6-11]. As a transcription factor, Stat3 is activated by phosphorylation; after dimerization it translocates into the nucleus, where it binds to the DNA, activating specific cellular pathways [12].

Elevated levels of Stat3 have been highlighted in various types of cancer, including thyroid cancer, melanoma, prostate cancer, Hodgkins lymphoma, breast cancer, hepatocellular carcinoma and glioblastoma [11, 13]. Being involved in numerous signalling pathways and overexpressed in tumour cells compared to normal tissues, Stat 3 is considered to be a potential target for future antitumor therapies $[10,12]$.

In vitro studies have demonstrated the role of Stat3 in glial tumour biology, especially in glioblastoma, being directly involved in maintaining the stem-like phenotype, EMT (epithelial-mesenchymal transition), resistance to alkylating agents such as temozolomide (TMZ) and radiotherapy $[5,14,15]$. Furthermore, in vitro inhibition of Stat3 activation in glioblastoma resulted in a decrease in the proliferative capacity and an increase in cellular sensitivity to TMZ treatment $[10,15,16]$. Although there a wide a range of in vitro studies showing the importance of Stat 3 in glioblastoma, there are only a few clinically oriented studies that correlate Stat3 expression with patient survival [17-19].

In this study, we evaluated the prognostic role of the immunohistochemical expression of p-Stat3Y705 in a series of primary glioblastoma patients. In addition, we attempted to establish a threshold for the immunohistochemical expression of this marker that has prognostic significance.

\section{Methods}

\section{Patients}

This retrospective study included 94 patients diagnosed with glioblastoma. Formalin-fixed paraffin-embedded tissue samples were obtained from the archive of the Emergency County Hospital Pathology Department in Cluj-Napoca, Romania. The patients were operated in the period 2009-2015 in the Neurosurgery Department of the same institution. All patients underwent the standard postoperative treatment (chemotherapy and radiotherapy). Patients were regularly checked according to standard protocols. The overall survival time was measured from the time of the first diagnosis of glioblastoma until death.

The diagnosis of glioblastoma was confirmed by two experienced pathologists (SS and DC) in line with the current WHO classification system [1]. We examined the medical record of each patient to determine age, gender, tumour volume (calculated by the product of the three diameters of the tumor divided by 2 [20], tumour localization, relapse and survival.

The study was conducted with the approval of the Ethics Committee of the Iuliu Hațieganu University of Medicine and Pharmacy Cluj-Napoca, Romania.

\section{Immunohistochemistry}

Immunohistochemistry was performed automatically on 3- $\mu$ m-thick sections of formalin-fixed and paraffinembedded tumour specimens with DAKO Omnis ${ }^{\circ}$, using the ethylenediaminetetraacetic acid (EDTA), at $\mathrm{pH}=9$, for antigen retrieval. For the immunohistochemical assessment of Stat3 expression, the specimens were incubated overnight at $4{ }^{\circ} \mathrm{C}$ with Phospho-Stat3 (Tyr705) antibody, clone D3A7 (Cell Signalling Technology, Inc., Danvers, $\mathrm{MA})$ at a 1:400 dilution. Positive and negative controls were used in line with the recommendation of the manufacturer. We assessed the percentage of Stat 3 positive tumour cells $(0-100 \%)$ and immunostaining intensity (absent, poor, moderate or intense). For all cases the area of necrosis was assessed by morphometry, using an Olympus BX 46 microscope. Images were taken with an Olympus UC 30 camera system with UI52 with an infinity correction optical system and processed in the LabSense 1.2 Olympus Software by GmbH Imaging Solutions.

The slides were read independently by two experienced pathologists with no knowledge of clinical data. In the case of divergent results, the slides were reviewed by both pathologists working together, and consensus was reached. The $\mathrm{K}$ score for the two pathologists that analysed the specimens was 0.81 .

\section{Statistical analysis}

Categorical data were presented as absolute and relative frequencies. Continuous data that did not follow the normal distribution were presented as the median and interquartile range (IQR). Overall survival (OS) was defined as the period from the primary surgery until death of the patient. We considered a $20 \%$ positivity of tumour cells as a cut-off for STAT3 immunopositivity, which respected the proportional hazard assumption for the Cox regression. The cut-off point was initially set to $>0$, $>5 \%$, and then increased to $10 \%$, and then $20 \%$. We increased the cut-off points because the proportional hazard assumption was not met for $>0,5,10 \%$, but it was met for $20 \%$. Comparisons between groups in respect of survival were performed using the long-rank test, and 
presented with a Kaplan Meier plot. The STAT3 immunopositivity was assessed univariately and then in a multivariate model (adjusting for age and tumour localization) using Cox proportional hazards regression analysis. We checked the proportional hazard assumption with a formal test. Results were expressed as a hazard ratio and its corresponding 95\% confidence interval. A two tailed $p$-value less than 0.05 was considered as statistically significant. All analyses were performed in $\mathrm{R}$ environment for statistical computing and graphics, version 3.2.3.

\section{Results}

Table 1 presents the characteristics of the patients included in our study by age, gender, tumour volume, location and clinical evolution (death and relapse).

Regarding localization, the tumours were mainly located in the frontal, parietal, temporal and occipital lobes. Other locations included: brainstem, cerebellum, pineal zone, basal ganglia, corpus callosum. All patients received multimodal treatment (surgery followed by radiotherapy and chemotherapy). Data regarding the actual treatment received were available for 53 patients (44 received both radiotherapy and chemotherapy, and three received radiotherapy). The doses were $75 \mathrm{mg} / \mathrm{m}^{2}$ for TMZ, and 60 Gy in 15 fractions for the radiotherapy.

\section{Stat3 immunohistochemistry}

We found p-Stat3 Y705 immunopositive cells in $89 \%$ of our glioblastoma cases. The percentage of p-Stat3 Y705

Table 1 Patient characteristics

\begin{tabular}{ll}
\hline Characteristic & $\mathrm{N}(\%)($ Total = 94) \\
\hline Age (yr.) median (IQR) & $51.5(44-56)$ \\
Gender & \\
M & $53(56.4)$ \\
F & $41(43.6)$ \\
Deceased & $88(93.62)$ \\
Relapse & $24(25.5)$ \\
Tumor volume $\left(\mathrm{cm}^{3}\right)$ median (IQR) & $23.26(10.35-44.81)$ \\
Localization & \\
$\quad$ Left & $37(39.4)$ \\
Right & $38(40.4)$ \\
Bilateral & $6(6.4)$ \\
$\quad$ n.a. & $13(13.8)$ \\
Frontal & $45(47.87)$ \\
Parietal & $22(23.4)$ \\
Temporal & $28(29.79)$ \\
Occipital & $12(12.77)$ \\
Brainstem & $2(2.13)$ \\
Other & $11(11.7)$ \\
\hline
\end{tabular}

positive cells was low, with less than $5 \%$ positive cells in $18(19.78 \%)$ cases, intermediate, with positive cells between 5 and $9 \%$ in $23(25.27 \%)$ cases, and high, with more than $10 \%$ Stat 3 positive cells in 50 (54.95\%) cases. The intensity of the nuclear staining was absent in 10 $(11 \%)$, poor in $43(47.3 \%)$, moderate in $36(39.6 \%)$ and intense in $2(2.2 \%)$ of the cases. To assess the immunohistochemical marker, the entire tumour surface was analysed. This has the advantage of highlighting the number of positive cells, the intensity of the marker, and the distribution of positive cells across the entire tumour surface. In our series, we could observe heterogeneity, the cells being positive for p-Stat3 Y705 at the nuclear level mainly in the perinecrotic areas and at the tumour invasion front (Figs. 1 and 2).

p-Stat3 Y705 immunohistochemical expression influences survival in glioblastoma. We found a statistically significant survival difference between subjects with more than $20 \%$ p-Stat3 Y705 positive cells (17 months median follow-up), who had better survival rates than those with less than $20 \%$ positive cells ( 8 months median follow-up), $p<0.001$, log-rank test (Fig. 3).

The same observation holds true in the Cox proportional hazards regression (HR) model in univariate and then in multivariate analyses, including p-Stat3 Y705 expression status $(>20 \%)$ even after adjusting for age and different tumour localization (Table 2). Age remains an important survival predictor. Localization was not associated with survival, and only parietal localization was close to the statistically significant level as a predictor factor. Furthermore, we created other models to adjust for other prognostic factors besides $\mathrm{p}$-Stat3 expression (Table 3). Thus, we added gender, tumour volume, and necrosis, and p-Stat3 Y705 expression status was an independent prognostic factor in glioblastoma $(P<0.001)$. None of the adjusted factors was statistically significant associated with survival, except age and parietal localization.

\section{Discussion}

In this study, we evaluated the p-Stat3y705 expression in a group of primary glioblastomas by immunohistochemistry and correlated the expression with the overall survival. In our study, an increased number of immunopositive pStat3y705 cells correlated with a reduced overall survival. Our data are in line with those of previous studies reporting that an increase of Stat3 level associates with a poor prognosis in glioblastoma patients, highlighting the clinical value of Stat3 evaluation for patients with glioblastoma [17-19]. These results support the importance of a routine immunohistochemical evaluation of the phosphorylation status of p-Stat3y705 as a prognostic marker of clinical interest for patients with glioblastoma regardless of age or relapse status. 


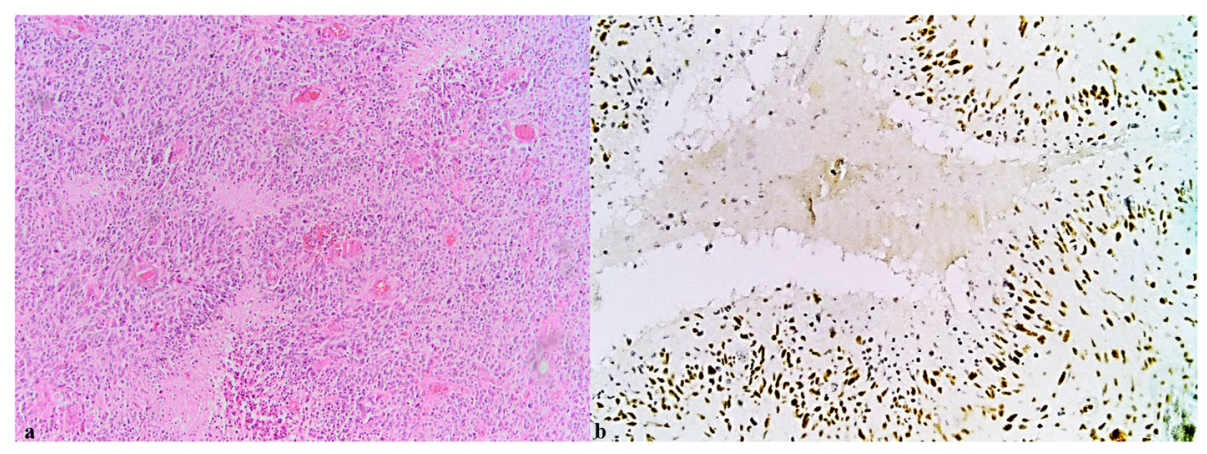

Fig. 1 a Necrosis is one of the histologic hallmarks of glioblastoma. Necrotic areas are usually seen in a serpentine or geographic pattern. Tumour cells migrate away creating a moving wave of palisading cells around the necrotic areas. (HE 10X) $\mathbf{b}$ Immunohistochemical expression of p-Stat3Y705 at the nuclear level. The cells are positive mainly in areas with hypoxia located around the necrosis (20X)

It is important to note that by evaluating the whole tumour surface, we observed a specific localization for Stat3 immunopositivity in cells that surround the necrotic areas, but also in cells located at the tumour invasion front. This suggests the presence of an intratumoural heterogeneity of cells in terms of the activated intracellular signalling pathways and could account for the resistance of a subset of cells to the current treatment, and the high relapse rate.

The perinecrotic localization of p-Stat3y705 immunopositive cells suggests the activation of the signalling pathways involved in cellular adaptation to hypoxia, Stat3 being a potent activator of HIF- $1 \alpha$, and VEGF $[19,21]$. HIF-1 can also be activated by mTOR proteins, either directly or via the STAT3 pathway [22, 23]. HIF-1 is known to be involved in stimulating tumour motility and radio resistance to current therapies, explained by the formation of "palisades" due to an outward migration of tumour cells toward the more vascularised zones [19, 24, 25]. VEGF can be up-regulated either by Stat3 and/or by HIF-1. Through its expression, it promotes the activation of neoangiogenesis in glioblastoma, highlighting the role of Stat3 in cellular adaptation in extreme conditions [7, 21, 26]. Furthermore, Stat3 is an activator of the epithelial-mesenchymal transition (EMT) process in glioblastoma, both through TGF $\beta$ and HIF- $1 \alpha$, thus enhancing tumour high motility, invasiveness and chemo resistance, which could account for the positivity of cells at the invasion front [27-30]. HIF-1 and Stat3 can also activate the transcription of zinc finger transcription factor (ZEB) proteins, especially ZEB1, which promotes EMT, migration and invasion [31, 32]. Stat3 activation in the invasion front cells could be an important observation. After surgical resection, these cells dispersed in the normal brain are at the origin of tumour recurrence. Developing inhibitors that target the signalling pathways activated specifically in cells at the tumour invasion front could lead to a more effective postoperative therapy.

Glioma stem cells (GSC) are a subtype of cells found in glioblastoma that are involved in tumour recurrence, initiation and invasiveness [33]. GSC are also believed to be involved in tumour chemo- and radio resistance to therapy [34]. CD133, a surface protein, is a known marker for GSC, its expression being correlated with tumour malignancy [23]. In low oxygenated cells, HIF$1 \alpha$, mTOR, TGF $\beta$ and Stat3 levels were shown to increase CD133 expression in tumour cells, promoting

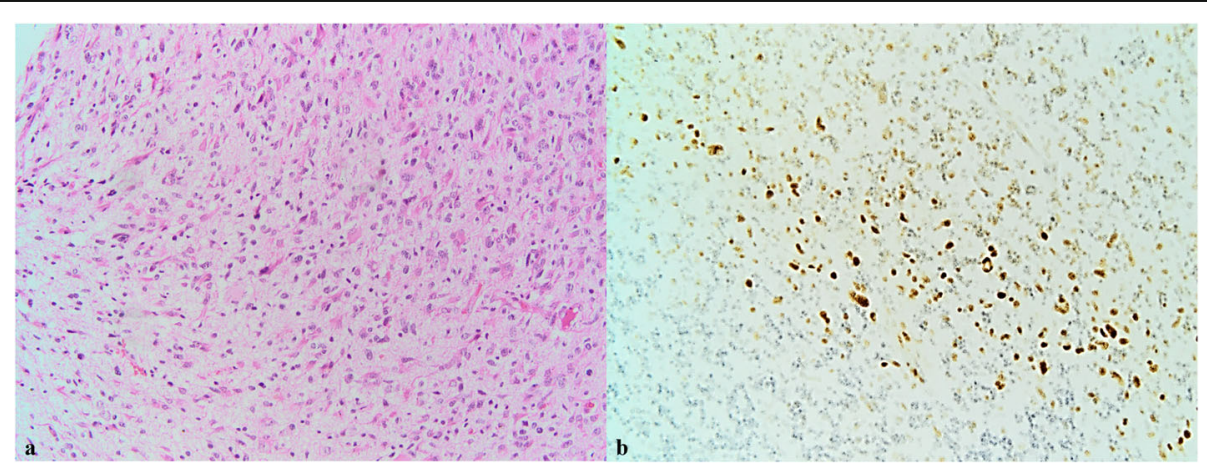

Fig. 2 a Tumour cells dispersed in the normal brain (HE 20X). b Immunohistochemical expression for p-Stat3Y705 at the tumour invasion front. We can evidence an increased intensity of expression where the tumour invades the normal brain tissue (20X) 


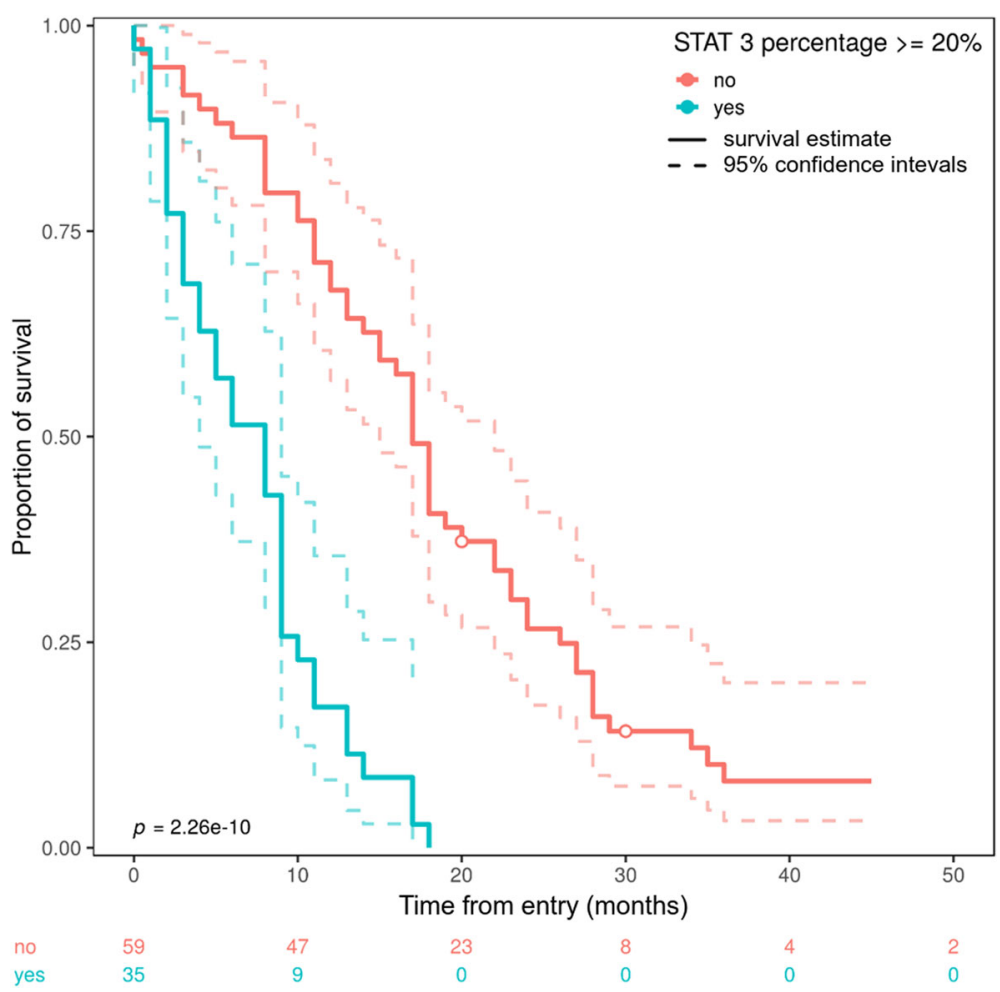

Fig. 3 Cumulative overall survival of 94 patients with glioblastoma comparing subjects with less than 20\% p-Stat3Y705 positive cells and those with more than $20 \%$ positive cells

GSC formation and proliferation $[6,9,14,35,36]$. Altogether, hypoxia and Stat3 are involved in promoting glioblastoma stem-like cells, thus increasing tumour resistance and invasiveness [37-39].

O6-methylguanyl DNA methyltransferase (MGMT) is an enzyme that helps repair the damaged DNA sequence in glioblastoma, preventing alkylating chemotherapic agents such as TMZ to be fully efficient [40]. Epigenetic hypermethylation of the MGMT promoter silences the gene predicting a favourable response to alkylating chemotherapy in glioblastoma patients [41, 42]. Therefore, MGMT promoter methylation status can be used as a marker for resistance to treatment with alkylating agents, especially in elderly patients, where chemotherapy in un-methylated tumours evidenced minimal benefit $[40,43]$. Stat3 expression is required for MGMT activity, and inhibition of Stat3 leads to a downregulation of MGMT, favouring TMZ therapy [16].

Regarding the in vitro studies that have evaluated Stat3 inhibition in GMB, Han el al showed that Cpd188 is able to enhance the effect of chemo-radiotherapy treatment

Table 2 Univariate and multivariate Cox proportional hazard regression models predicting overall survival

\begin{tabular}{|c|c|c|c|c|c|c|}
\hline & \multicolumn{3}{|c|}{ Univariable } & \multicolumn{3}{|c|}{ Multivariable } \\
\hline & $\overline{\mathrm{HR}}$ & $(95 \% \mathrm{Cl})$ & $p$-value & $\overline{\mathrm{HR}}$ & $(95 \% \mathrm{Cl})$ & $p$-value \\
\hline Age (years) & 1.02 & $(1-1.05)$ & 0.039 & 1.04 & $(1.01-1.06)$ & 0.01 \\
\hline p-Stat3 percentage $\geq 20 \%$ & 4.86 & $(2.91-8.11)$ & $<0.001$ & 5.69 & $(3.27-9.91)$ & $<0.001$ \\
\hline Frontal & 0.84 & $(0.55-1.28)$ & 0.419 & 1.02 & $(0.61-1.71)$ & 0.945 \\
\hline Parietal & 0.86 & $(0.52-1.41)$ & 0.555 & 0.6 & $(0.35-1.04)$ & 0.068 \\
\hline Temporal & 0.94 & $(0.59-1.49)$ & 0.799 & 0.84 & $(0.5-1.42)$ & 0.522 \\
\hline Occipital & 0.81 & $(0.44-1.5)$ & 0.511 & 0.81 & $(0.4-1.64)$ & 0.562 \\
\hline Brainstem & 1.24 & $(0.3-5.07)$ & 0.764 & 2.91 & $(0.62-13.75)$ & 0.177 \\
\hline
\end{tabular}

The multivariate model includes all the variables in the table

A second model was created adding to these variables, gender, as well as tumour volume $\left(\mathrm{cm}^{3}\right)$, where we found $\mathrm{HR}$ p-Stat3 percentage $\geq 20 \%=4.86(95 \% \mathrm{Cl}$ 2.91-8.11), $p<0.001$

HR Hazard ratio, $\mathrm{Cl}$ Confidence interval 
Table 3 Multivariate Cox proportional hazard regression models predicting overall survival, for p-Stat3 percentage adjusting for different confounders

\begin{tabular}{llll}
\hline Models & HR & $(95 \% \mathrm{Cl})$ & $P$-value \\
\hline Model 1 & 5.69 & $(3.27-9.91)$ & $<0.001$ \\
Model 2 & 4.86 & $\mathrm{Cl} 2.91-8.11$ & $<0.001$ \\
Model 3 & 7.8 & $(2.88-21.11)$ & $<0.001$ \\
\hline
\end{tabular}

Model 1 - multivariate Cox proportional hazard regression model including age (years), Stat 3 percentage $>=20 \%$, localizations (frontal, parietal, temporal, occipital, brainstem)

Model 2 - model 1 plus gender and tumour volume $\left(\mathrm{cm}^{3}\right)$

Model 3 - model 2 plus necrosis $\left(\mu \mathrm{m}^{2}\right)$

$H R$ Hazard ratio, $\mathrm{Cl}$ Confidence interval

for the cell lines with a p-Stat overexpression [44]. Another study has provided data regarding molecular mechanisms underlying hypoxia-induced glioma cell autophagy, evidencing that the inhibition of IL6-Stat3 axis represses autophagy in glioblastoma cell lines in vitro [45]. The same study has demonstrated a certain level of efficiency by blocking 116 receptor with tocilizumab. Given that Stat3 is situated at the interconnection of signalling pathways that controls the cellular processes involved in hypoxia, resistance to treatment, EMT, the stem-like phenotype and migration, it could be interesting to consider STAT3 inhibitors as a potentially therapeutic approach in glioblastoma treatment $[15,16,46]$.

Stat3 inhibitors are currently an important issue, as early clinical data has shown promising results in EGFR mutation- positive non-small cell lung cancer. However, more research is required to understand the different mechanisms that lead to the activation of STAT3 in order to design robust Stat3-targeted therapies [15]. Another example of inhibitors targeting Stat3 at different levels and currently used in clinical trials are: STAT3 antisense oligonucleotide (advanced stage/metastatic hepatocellular carcinoma) or STAT3 $\mathrm{SH} 2$ domain binder (multiple myeloma, non-Hodgkin lymphoma, acute myeloid leukaemia, chronic myeloid leukaemia) [47]. Overall, these data could open the perspective for future clinical trials using Stat3 inhibitors in glioblastoma.

As with any observational study, potential confounders that were not taken into account could influence the observed results. We used multivariate analysis and we adjusted for several variables, but we didn't include the different treatment timing/dosages.

\section{Conclusion}

Our results show that Stat3 expression can be evaluated by immunohistochemistry and has an important prognostic role in glioblastoma. Therefore, clinical approaches should consider including a Stat3 inhibitor in the therapeutic protocol in order to improve tumour response to radiotherapy and chemotherapy. Furthermore, another observation of our study is the preferred localization of
Stat3 positive cells at the nuclear level of tumour cells in the perinecrotic areas and at the tumour invasion front. This discovery could suggest the presence of heterogeneous cell populations that are involved in tumour development and treatment resistance. In order to better understand the malignant potential of glioblastomas, we should consider glioblastoma consists of distinct cell subpopulations. This approach could uncover molecular contexts of susceptibility that will accelerate the development of new therapies targeting cells that matter.

\section{Abbreviations \\ Cl: Confidence interval; EDTA: Ethylenediaminetetraacetic acid; EMT: Epithelial-mesenchymal transition; GSC: Glioma stem cells; HE: Hematoxylin-Eozin; HIF-1a: Hypoxic inducible factor 1a; HR: Hazard regression; IQR: Interquartile range; MGMT: O6-methylguanyl DNA methyltransferase; mTOR: Mammalian target of rapamycin; OS: Overall survival; Stat3: Signal transducer and activator of transcription 3; TGFß: Transforming growth factor beta; TMZ: Temozolomide; VEGF: Vascular endothelial growth factor; yr.: Years; ZEB: Zinc finger transcription factor}

\section{Acknowledgements}

Not applicable.

\section{Authors' contributions}

SS designed the study, did the histological and immunohistochemical analysis of the samples, participated in writing the manuscript; RP collected the clinical data and took the histological samples from the archives, participated in writing the manuscript; DL did the statistical analysis; CM did the imaging diagnosis and follow-up of the tumours; IM and SIF performed the surgical intervention and clinical follow-up; VAP and AOM searched the archives and collected data about the patients and tumours; AOM participated in writing and editing the manuscript. All authors read and approved the final manuscript.

\section{Funding}

The study was supported by an internal grant (code 4944/4/08.03/2016) from the luliu Hațieganu University of Medicine and Pharmacy, Cluj-Napoca, Romania.

Availability of data and materials

The datasets used and/or analysed during the current study are available from the corresponding author on reasonable request.

\section{Ethics approval and consent to participate}

The study was conducted with the approval of the Ethics Committee of Iuliu Hațieganu University of Medicine and Pharmacy, Cluj-Napoca, Romania.

Consent for publication

Not applicable.

Competing interests

The authors declare that they have no competing interests.

\section{Author details}

${ }^{1}$ Department of Morphological Sciences, luliu Hațieganu University of Medicine and Pharmacy, 6 Pasteur Street, 400349 Cluj-Napoca, Romania. ${ }^{2}$ Department of Pathology, Imogen Research Centre, Cluj-Napoca, Romania. ${ }^{3}$ Department of Medical Informatics and Biostatistics, Iuliu Hațieganu University of Medicine and Pharmacy, Cluj-Napoca, Romania. ${ }^{4}$ Department of Neurosurgery, luliu Hațieganu University of Medicine and Pharmacy, Cluj-Napoca, Romania. ${ }^{5}$ Department of Neurosurgery, Emergency County Hospital, Cluj-Napoca, Romania. ${ }^{6}$ Department of Pathology, Emergency County Hospital, Cluj-Napoca, Romania. 
Received: 23 April 2019 Accepted: 14 October 2019 Published online: 05 November 2019

\section{References}

1. Louis DN, Perry A, Reifenberger G, von Deimling A, Figarella-Branger D, Cavenee WK, et al. The 2016 World Health Organization classification of tumors of the central nervous system: a summary. Acta Neuropathol. 2016; 131:803-20. https://doi.org/10.1007/s00401-016-1545-1.

2. $\quad$ Wen PY, Kesari S. Malignant gliomas in adults. N Engl J Med. 2008;359:492507. https://doi.org/10.1056/NEJMra0708126.

3. Stupp R, Mason WP, van den Bent MJ, Weller M, Fisher B, Taphoorn MJB, et al. Radiotherapy plus concomitant and adjuvant temozolomide for glioblastoma. N Engl J Med. 2005;352:987-96. https://doi.org/10.1056/ NEJMoa043330

4. Kubelt C, Hattermann K, Sebens S, Mehdorn HM, Held-Feindt J. Epithelial-to-mesenchymal transition in paired human primary and recurrent glioblastomas. Int J Oncol. 2015;46:2515-25. https://doi.org/10. 3892/ijo.2015.2944.

5. Kahlert UD, Nikkhah G, Maciaczyk J. Epithelial-to-mesenchymal(-like) transition as a relevant molecular event in malignant gliomas. Cancer Lett. 2013;331:131-8. https://doi.org/10.1016/j.canlet.2012.12.010.

6. Platet N, Liu SY, El Atifi M, Oliver L, Vallette FM, Berger F, et al. Influence of oxygen tension on CD133 phenotype in human glioma cell cultures. Cancer Lett. 2007;258:286-90. https://doi.org/10.1016/j.canlet.2007.09.012.

7. Yokogami K, Yamashita S, Takeshima H. Hypoxia-induced decreases in SOCS3 increase STAT3 activation and upregulate VEGF gene expression. Brain Tumor Pathol. 2013;30:135-43. https://doi.org/10.1007/s10014-0120122-0.

8. Fukumura D, Xu L, Chen Y, Gohongi T, Seed B, Jain RK. Hypoxia and acidosis independently up-regulate vascular endothelial growth factor transcription in brain tumors in vivo. Cancer Res. 2001:61:6020-4.

9. Matsumoto K, Arao T, Tanaka K, Kaneda H, Kudo K, Fujita Y, et al. mTOR signal and hypoxia-inducible factor-1 regulate CD133 expression in cancer cells. Cancer Res. 2009;69:7160-4. https://doi.org/10.1158/00085472.CAN-09-1289.

10. Kim JE, Patel M, Ruzevick J, Jackson CM, Lim M. STAT3 activation in glioblastoma: biochemical and therapeutic implications. Cancers (Basel). 2014;6:376-95. https://doi.org/10.3390/cancers6010376.

11. Bromberg J. Stat proteins and oncogenesis. J Clin Invest. 2002;109:1139-42. https://doi.org/10.1172/JCl15617.

12. Gray GK, McFarland BC, Nozell SE, Benveniste EN. NF-kB and STAT3 in glioblastoma: therapeutic targets coming of age. Expert Rev Neurother. 2014;14. https://doi.org/10.1586/14737175.2014.964211.

13. Zuo M, Li C, Lin J, Javle M. LLL12, a novel small inhibitor targeting STAT3 for hepatocellular carcinoma therapy. Oncotarget. 2015;6:10940-9. https://doi. org/10.18632/oncotarget.3458.

14. Kim E, Kim M, Woo D-H, Shin Y, Shin J, Chang N, et al. Phosphorylation of EZH2 activates STAT3 signaling via STAT3 methylation and promotes tumorigenicity of glioblastoma stem-like cells. Cancer Cell. 2013;23:839-52. https://doi.org/10.1016/j.ccr.2013.04.008.

15. Wong ALA, Hirpara JL, Pervaiz S, Eu J-Q, Sethi G, Goh B-C. Do STAT3 inhibitors have potential in the future for cancer therapy? Expert Opin Investig Drugs. 2017;26:883-7. https://doi.org/10.1080/13543784.2017. 1351941.

16. Kohsaka S, Wang L, Yachi K, Mahabir R, Narita T, Itoh T, et al. STAT3 inhibition overcomes temozolomide resistance in glioblastoma by downregulating MGMT expression. Mol Cancer Ther. 2012;11:1289-99. https://doi.org/10.1158/1535-7163.MCT-11-0801.

17. Lin G-S, Chen Y-P, Lin Z-X, Wang X-F, Zheng Z-Q, Chen L. STAT3 serine 727 phosphorylation influences clinical outcome in glioblastoma. Int J Clin Exp Pathol. 2014;7:3141-9.

18. Birner P, Toumangelova-Uzeir K, Natchev S, Guentchev M. STAT3 tyrosine phosphorylation influences survival in glioblastoma. J Neuro-Oncol. 2010; 100:339-43. https://doi.org/10.1007/s11060-010-0195-8

19. Rodrigues BR, Queiroz-Hazarbassanov N, Lopes MH, Bleggi-Torres LF, Suzuki S, Cunha IW, et al. Nuclear unphosphorylated STAT3 correlates with a worse prognosis in human glioblastoma. Pathol Res Pract. 2016;212:517-23. https://doi.org/10.1016/j.prp.2016.03.001

20. Sreenivasan S, Madhugiri V, Sasidharan G, Kumar RR. Measuring glioma volumes: a comparison of linear measurement based formulae with the manual image segmentation technique. J Cancer Res Ther. 2016;12:161. https://doi.org/10.4103/0973-1482.153999.

21. Xu Q, Briggs J, Park S, Niu G, Kortylewski M, Zhang S, et al. Targeting Stat3 blocks both HIF-1 and VEGF expression induced by multiple oncogenic growth signaling pathways. Oncogene. 2005;24:5552-60. https://doi.org/10. 1038/sj.onc.1208719.

22. Huang W-J, Chen W-W, Zhang X. Glioblastoma multiforme: effect of hypoxia and hypoxia inducible factors on therapeutic approaches. Oncol Lett. 2016; 12:2283-8. https://doi.org/10.3892/ol.2016.4952.

23. Dodd KM, Yang J, Shen MH, Sampson JR, Tee AR. mTORC1 drives HIF-1a and VEGF-A signalling via multiple mechanisms involving 4E-BP1, S6K1 and STAT3. Oncogene. 2015;34:2239-50. https://doi.org/10.1038/onc.2014.164.

24. Brat DJ, Castellano-Sanchez AA, Hunter SB, Pecot M, Cohen C, Hammond $\mathrm{EH}$, et al. Pseudopalisades in glioblastoma are hypoxic, express extracellular matrix proteases, and are formed by an actively migrating cell population. Cancer Res. 2004;64:920-7.

25. Rong Y, Durden DL, Van Meir EG, Brat DJ, "Pseudopalisading" necrosis in glioblastoma: a familiar morphologic feature that links vascular pathology, hypoxia, and angiogenesis. J Neuropathol Exp Neurol. 2006;65:529-39.

26. Spence AM, Muzi M, Swanson KR, O'Sullivan F, Rockhill JK, Rajendran JG, et al. Regional hypoxia in glioblastoma multiforme quantified with [18F] fluoromisonidazole positron emission tomography before radiotherapy: correlation with time to progression and survival. Clin Cancer Res. 2008;14: 2623-30. https://doi.org/10.1158/1078-0432.CCR-07-4995.

27. Lo H-W, Cao X, Zhu H, Ali-Osman F. Constitutively activated STAT3 frequently coexpresses with epidermal growth factor receptor in highgrade gliomas and targeting STAT3 sensitizes them to Iressa and alkylators. Clin Cancer Res. 2008;14:6042-54. https://doi.org/10.1158/ 1078-0432.CCR-07-4923.

28. Liu R-Y, Zeng Y, Lei Z, Wang L, Yang H, Liu Z, et al. JAK/STAT3 signaling is required for TGF- $\beta$-induced epithelial-mesenchymal transition in lung cancer cells. Int J Oncol. 2014;44:1643-51. https://doi. org/10.3892/ijo.2014.2310

29. Herrera-Perez RM, Voytik-Harbin SL, Sarkaria JN, Pollok KE, Fishel ML, Rickus $J$. Presence of stromal cells in a bioengineered tumor microenvironment alters glioblastoma migration and response to STAT3 inhibition. PLoS One. 2018;13:e0194183. https://doi.org/10.1371/journal.pone.0194183.

30. Cruickshanks N, Zhang Y, Hine S, Gibert M, Yuan F, Oxford M, et al. Discovery and therapeutic exploitation of mechanisms of resistance to MET inhibitors in glioblastoma. Clin Cancer Res. 2019;25:663-73. https://doi.org/ 10.1158/1078-0432.CCR-18-0926.

31. Jhanwar-Uniyal M, Labagnara M, Friedman M, Kwasnicki A, Murali R. Glioblastoma: molecular pathways, stem cells and therapeutic targets. Cancers (Basel). 2015;7:538-55. https://doi.org/10.3390/cancers7020538.

32. Chou C-C, Chuang H-C, Salunke SB, Kulp SK, Chen C-S. A novel HIF-1aintegrin-linked kinase regulatory loop that facilitates hypoxia-induced HIF-1a expression and epithelial-mesenchymal transition in cancer cells. Oncotarget. 2015;6:8271-85. https://doi.org/10.18632/oncotarget.3186

33. Zhang W, Shi X, Peng Y, Wu M, Zhang P, Xie R, et al. HIF-1a promotes epithelial-mesenchymal transition and metastasis through direct regulation of ZEB1 in colorectal cancer. PLoS One. 2015;10. https://doi.org/10.1371/ journal.pone.0129603.

34. Chen $\mathrm{K}$, Huang $\mathrm{Y}$, Chen J. Understanding and targeting cancer stem cells: therapeutic implications and challenges. Acta Pharmacol Sin. 2013;34:73240. https://doi.org/10.1038/aps.2013.27.

35. Zorzan M, Giordan E, Redaelli M, Caretta A, Mucignat-Caretta C. Molecular targets in glioblastoma. Future Oncol. 2015;11:1407-20. https://doi.org/10. 2217/fon.15.22.

36. You H, Ding W, Rountree CB. Epigenetic regulation of cancer stem cell marker CD133 by transforming growth factor- $\beta$. Hepatology. 2010;51:163544. https://doi.org/10.1002/hep.23544

37. Peñuelas S, Anido J, Prieto-Sánchez RM, Folch G, Barba I, Cuartas I, et al. TGF- $\beta$ increases glioma-initiating cell self-renewal through the induction of LIF in human glioblastoma. Cancer Cell. 2009;15:315-27. https://doi.org/10. 1016/j.ccr.2009.02.011.

38. Zhang C, Mukherjee S, Tucker-Burden C, Ross JL, Chau MJ, Kong J, et al. TRIM8 regulates stemness in glioblastoma through PIAS3-STAT3. Mol Oncol. 2017:11:280-94. https://doi.org/10.1002/1878-0261.12034.

39. Ganguly D, Sims M, Cai C, Fan M, Pfeffer LM. Chromatin remodeling factor BRG1 regulates stemness and chemosensitivity of glioma initiating cells. Stem Cells. 2018:36:1804-15. https://doi.org/10.1002/stem.2909. 
40. Guryanova OA, Wu Q, Cheng L, Lathia JD, Huang Z, Yang J, et al. Nonreceptor tyrosine kinase BMX maintains self-renewal and tumorigenic potential of glioblastoma stem cells by activating STAT3. Cancer Cell. 2011; 19:498-511. https://doi.org/10.1016/j.ccr.2011.03.004.

41. Wick W, Weller M, van den Bent M, Sanson M, Weiler M, von Deimling A, et al. MGMT testing - the challenges for biomarker-based glioma treatment. Nat Rev Neurol. 2014;10:372-85. https://doi.org/10.1038/nrneurol.2014.100.

42. Crespo I, Vital AL, Gonzalez-Tablas M, Patino Mdel C, Otero A, Lopes MC, et al. Molecular and genomic alterations in glioblastoma multiforme. Am J Pathol. 2015;185:1820-33. https://doi.org/10.1016/j.ajpath.2015.02.023.

43. Hegi ME, Diserens A-C, Gorlia T, Hamou M-F, de Tribolet N, Weller M, et al. MGMT gene silencing and benefit from temozolomide in glioblastoma. N Engl J Med. 2005;352:997-1003. https://doi.org/10.1056/NEJMoa043331.

44. Han TJ, Cho BJ, Choi EJ, Kim DH, Song SH, Paek SH, et al. Inhibition of STAT3 enhances the radiosensitizing effect of temozolomide in glioblastoma cells in vitro and in vivo. J Neuro-Oncol. 2016;130:89-98. https://doi.org/10.1007/s11060-016-2231-9.

45. Xue H, Yuan G, Guo X, Liu Q, Zhang J, Gao X, et al. A novel tumorpromoting mechanism of IL6 and the therapeutic efficacy of tocilizumab: hypoxia-induced IL6 is a potent autophagy initiator in glioblastoma via the p-STAT3-MIR155-3p-CREBRF pathway. Autophagy. 2016;12:1129-52. https:// doi.org/10.1080/15548627.2016.1178446

46. Haftchenary S, Luchman HA, Jouk AO, Veloso AJ, Page BDG, Cheng XR, et al. Potent targeting of the STAT3 protein in brain cancer stem cells: a promising route for treating glioblastoma. ACS Med Chem Lett. 2013;4: 1102-7. https://doi.org/10.1021/m/4003138.

47. Johnson DE, O'Keefe RA, Grandis JR. Targeting the IL-6/JAK/STAT3 signalling axis in cancer. Nat Rev Clin Oncol. 2018;15:234-48. https://doi.org/10.1038/ nrclinonc.2018.8.

\section{Publisher's Note}

Springer Nature remains neutral with regard to jurisdictional claims in published maps and institutional affiliations.

Ready to submit your research? Choose BMC and benefit from:

- fast, convenient online submission

- thorough peer review by experienced researchers in your field

- rapid publication on acceptance

- support for research data, including large and complex data types

- gold Open Access which fosters wider collaboration and increased citations

- maximum visibility for your research: over $100 \mathrm{M}$ website views per year

At $\mathrm{BMC}$, research is always in progress.

Learn more biomedcentral.com/submissions 